\title{
Hybrid non-linear model predictive control of a run-of-mine ore grinding mill circuit
}

\author{
S. Botha ${ }^{a}$, J.D. le Roux ${ }^{\mathrm{a}}$, I.K. Craig ${ }^{\mathrm{a}, *}$ \\ ${ }^{a}$ Department of Electrical, Electronic, and Computer Engineering, University of Pretoria, Pretoria, South \\ Africa.
}

\begin{abstract}
A hybrid non-linear model predictive controller (HNMPC) is developed for a run-of-mine ore grinding mill circuit. A continuous-time grinding mill circuit model is presented with a hydrocyclone cluster as the primary classifier. The discrete-time component is the switching of hydrocyclones in the hydrocyclone cluster. The resulting model is a hybrid non-linear model with both continuous and discrete dynamics. A simulation of the HNMPC shows the advantages of using the hydrocyclone cluster as an additional manipulated variable. The advantages of the HNMPC is illustrated by comparing its performance to a non-linear MPC where no switching of hydrocyclones is possible. The genetic algorithm based HNMPC showed increased controller stability in its ability to incorporate discrete dynamics into the controller directly. The methods discussed in this paper can be used to incorporate different types of discrete dynamics into advanced grinding mill circuit controllers due to the modular presentation of the model and HNMPC controller design.
\end{abstract}

Keywords: advanced process control, comminution, genetic algorithm, grinding mill, hydrocyclone cluster, hybrid modelling, hybrid non-linear model predictive control

\section{Introduction}

A run-of-mine (ROM) ore milling circuit is used to grind incoming ore bearing precious minerals to within a specification, e.g. $70 \%$ of the product particles must be smaller than $75 \mu \mathrm{m}$. The fine product produced from the milling circuit allows for the separation of the precious minerals from the gangue material [1]. In order to improve the recovery rate of the valuable metals in the downstream processes, the particles discharged from the grinding mill

\footnotetext{
The financial assistance of the National Research Foundation (DAAD-NRF) towards this research is hereby acknowledged. Opinions expressed and conclusions arrived at, are those of the author and are not necessarily attributed to the DAAD-NRF.

*Corresponding author. Address: Department of Electrical, Electronic, and Computer Engineering, University of Pretoria, Pretoria, South Africa.

Tel.: +27 12420 2172; fax: +27 123625000 .

Email address: ian.craig@up.ac.za (I.K. Craig)
} 
circuit should have a consistent quality, i.e. remain within specification [2]. Efficient control of the grinding mill circuit is therefore essential to achieve the desired product specifications in terms of throughput and quality.

Generally, the better the quality of a product, the lower the throughput of the plant, and vice versa [3]. Because of the interaction between the control objectives for quality and throughput, the aim is to maintain quality as close to the minimum specification as set by the downstream processes, thereby maximizing throughput even in the presence of large disturbances [3]. In addition to these control objectives, a grinding mill circuit controller should also aim to increase energy efficiency and at all times ensure process stability [4].

The downstream process requirements play a critical role in the steady-state optimisation objective of the grinding mill circuit. Although the local optimisation objectives for the grinding mill circuit is to maintain a constant product fineness and maximise throughput, the key revenue generating variable for the mineral processing plant is the concentrate grade of the downstream process (the separation circuit). In $[5,6]$ the product size distribution specification for the grinding mill circuit is continuously set by the separation circuit to improve the separation circuit's economic performance. An economic objective function is used in [7] where a predictive controller sets the targets for an advanced regulatory controller on the grinding circuit. The objective function optimised the income generated from the plant as a function of the feed ore grade to the grinding circuit, the separator tailings grade and the recovery of the plant.

The economic evaluation of a grinding mill circuit is done by using the relationship between the grinding mill circuit product particle size and the separation concentrate recovery and grade curve [8]. Economic plant-wide optimisation for a mineral processing plant is therefore limited to the operating range of the grinding mill circuit [9]. Due to this limitation, grinding mill circuit controllers should be designed to optimise over a wide range of steady-state regions, incorporate various different controlled- and manipulated variables $(\mathrm{MVs})$, and benefit from all dynamics in the circuit to reject upstream disturbances quickly. These findings are in line with [10] where a systematic procedure is given to find suitable controlled variables $(\mathrm{CVs})$ in order to construct a control architecture capable of achieving the plant-wide economic optimisation objective.

The norm for industrial milling circuit control is single-loop proportional-integral-derivative (PID) controllers despite strong interactions between the loops [11]. Single loop PID controllers do not allow for any trade-off between the control objectives. Therefore, if one of the loops hit a constraint, the other loops can not attempt to offset the resulting set-point error. A variety of multivariable controllers were developed to achieve the optimal trade of between the control objectives and improvements in product quality, throughput, and power consumption $[2,12,13,14]$.

The design of advanced multivariable controllers involves identifying additional MVs to improve the circuit's operating region $[15,16,17,18]$. In [15] the range of quality control was increased by independently manipulating the mill's water feed-rate instead of fixing the water feed-rate as a ratio of the ore feed-rate. Similarly in [18] the range of quality control was increased by manually switching cyclones in a hydrocyclone cluster. Power consumption reduction while maintaining quality was achieved in [19] by alternating between different 


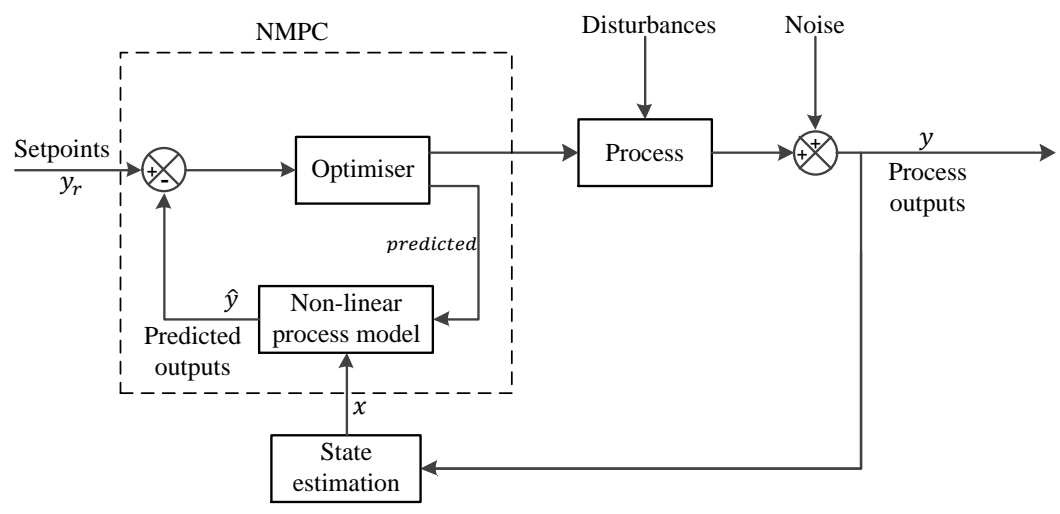

Figure 1: Non-linear model predictive control.

stockpiles as ore feed and whether a secondary grinding stage is used or not. In [16] and [17] the mill speed is used as an additional MV to reduce mill power consumption, and to independently control quality and throughput.

One of the most common advanced process control methods is model predictive control (MPC). MPC is a control technique where optimal control is applied in an iterative fashion [20]. The control problem is solved at each iteration based on the plant measurements, predicted states and the past control actions. The controller predicts the plant outputs (according to some dynamic plant model) over a prediction horizon given a vector of control moves. During controller execution an optimiser will estimate the optimal control moves over a control horizon, that drive the process to the desired operating point (defined by reference setpoints and optimisation objectives) according to an objective function based on the predicted plant outputs. Once the optimal control move vector is calculated only the first move is implemented and the process is repeated at the next execution interval [21]. Non-linear MPC (NMPC) follows the same principle of operation as a linear MPC, except a non-linear model is used to predict the plant outputs and the solver should be able to cope with possible local minima and non-linear models. The block diagram in Fig. 1 illustrates the NMPC principle.

The robust non-linear model predictive controller (MPC) developed in [3] showed that even in the presence of large disturbances and model mismatch it was possible to efficiently control a grinding mill circuit. The controller was capable of controlling over a larger operating region than linear MPC controllers such as the ones in $[2,13]$. Furthermore, due to the large non-linearities in the grinding mill circuit, a non-linear MPC capable of predicting and controlling the non-linear dynamics is highly desirable.

The key drawbacks in using model based predictive controllers is model mismatch because of the difficulty to estimate model parameters and complex solutions with unrealistic execution intervals [3, 20, 22]. The reduced complexity model in [1] was proven qualitatively accurate and uses as few parameters and states as possible. The model made it possible to design the robust non-linear MPC of [3]. Although the controller was not feasible for online 
application at the time, technological improvements (in the form of multi-core processors) have made it possible to implement non-linear MPC controllers with complex models in real time [23]. A drawback of non-linear MPC controllers is that discrete components in the circuit cannot be integrated directly in the controller [24]. This leaves certain tasks to operator intervention and could result in sub-optimal operation.

Hybrid model predictive control (HMPC) is capable of controlling a process by predicting according to continuous- and discrete-time events, and manipulating continuous and discrete components [25, 26]. In [19] a linear HMPC was implemented to select which stockpile to feed from or if the secondary grinding stage should be active. Similarly, [27] gives a framework for HMPC of grinding mill circuits, where linear steady-state models are considered. The models are converted to a specific class of hybrid systems and then specialised packages such as HYSDEL are used to generate and solve the objective function [27, 28]. These set methods of solving the hybrid model and control problem ensure reasonable controller execution time.

The work in this study builds on [18] where the benefits of switching hydrocyclones in and out of a cluster are shown. The novel approach in this paper is the on-line switching of hydrocyclones in a cluster with the use of HNMPC. The controller benefits from a larger operating region due to the non-linear model, and being able to switch the discrete components thereby further increasing the operating region. The aim is to show that more effective control of a grinding mill circuit can be achieved in the presence of disturbances compared to conventional non-linear MPC. A full non-linear model is used to capture the dynamic continuous time properties of the circuit, and the model is adapted to contain the discrete dynamics of the hydrocyclone cluster switching. HNMPC is achieved by using a genetic algorithm in order to minimize the objective function.

Section 2 gives a discription of the process and the full hybrid non-linear model is discussed in Section 3. The controller design is given Section 4 and the simulation results of a non-linear MPC and HNMPC under identical conditions are given in Section 5. The final discussion is given in Section 6 .

\section{Process Description}

A closed single-stage grinding mill circuit with a hydrocyclone cluster is shown in Fig. 2. The circuit consists of a semi-autogenous (SAG) mill with an end-discharge screen, a sump and a hydrocyclone cluster. The end-discharge screen consists of a grate and a pulp lifter. The mill receives four different input streams from a feeder module: run-of-mine ore $(M F O)$, water $(M F W)$, steel balls $(M F B)$ and underflow from the hydrocyclone cluster. Water is added to assist with the transport of particles and steel balls are added to assist with the breakage of rocks in the mill. The fraction of the mill volume filled with water, ore and steel balls is represented by $J_{T}$. The mill is the most power intensive element in a grinding mill circuit and the power draw of the mill motor is represented by $P_{\text {mill }}$ [4]. The slurry mixture of ground ore and water in the mill is discharged into the sump through an end-discharge screen that limits the particle size of the discharged slurry. The level of the slurry in the 
sump is represented by $S V O L$. The slurry in the sump is diluted with additional water $(S F W)$ before it is pumped to the hydrocyclone cluster.

A hydrocyclone separates the particles smaller than the specification size from particles larger than the specification size. The control target is generally to grind ore such that a percentage of the ground ore falls below a specification size. The in-specification particles are discharged from the hydrocyclone overflow as a final product, while the out-ofspecification particles are recycled through the hydrocyclone underflow back to the mill for further grinding [1].

Grinding mill circuit designs can vary to use a hydrocyclone cluster instead of just one hydrocyclone. A hydrocyclone cluster allows for smaller cyclones to achieve a finer cut while maintaining high volumetric flow-rates [29]. For a cluster of hydrocyclones, $C F F$ is the total feed to the hydrocyclone cluster and $C F D$ is the density of the feed stream. The final product quality is referred to as the product particle size estimate $(P S E)$, which is the fraction of particles in the hydrocyclone cluster overflow smaller than the specification size. The throughput (THP) is the mass flow-rate of solids of the hydrocyclone cluster overflow. The commonly used variables for control of the grinding mill circuit are given in Table 1 [11].

\section{Process Model}

In this section the dynamic phenomenological non-linear population balance model of [1] is described, where the mill, sump and hydrocyclone are modelled separately. The hydrocyclone model is expanded to describe a cluster of hydrocyclones such that a non-linear hybrid model is created to describe the circuit in Fig. 2. The model uses fewer parameters and states for the mill and hydrocyclone than [30] and [31] do, mainly by using fewer size classes to characterise the material in the circuit. The study in [32] specifically looked at what the effect is on controller performance if the number of size classes is reduced. It was found that even with the reduced number of size classes, the model still gives sufficiently accurate results for process control without any noticeable loss in controller performance [32].

The model was fitted to industrial data, and validated in [1] for a range of operating conditions. It was found that the output variables of the model change in the correct directions with orders of magnitude similar to the validation dataset. The model was validated for process control, meaning it is not accurate enough for green fields grinding mill circuit design, but is qualitatively accurate and can be used for predictive controller design. This model forms the basis for the controller package StarCS RNMPC of Mintek [23].

The model uses three size classes to describe the material in the circuit: rocks, coarse ore and fine ore. The ore in the mill that is too large to pass through the end-discharge screen (larger than $22.4 \mathrm{~mm}$ ) are referred to as rocks. Material discharged through the enddischarge screen which is larger than the specification size (smaller than $22.4 \mathrm{~mm}$ but larger than $75 \mu \mathrm{m}$ ) is referred to as coarse ore, and material which is smaller than the specification size (smaller than $75 \mu \mathrm{m}$ ) is referred to as fine ore [1]. Solids are defined as the sum of fine and coarse ore. 


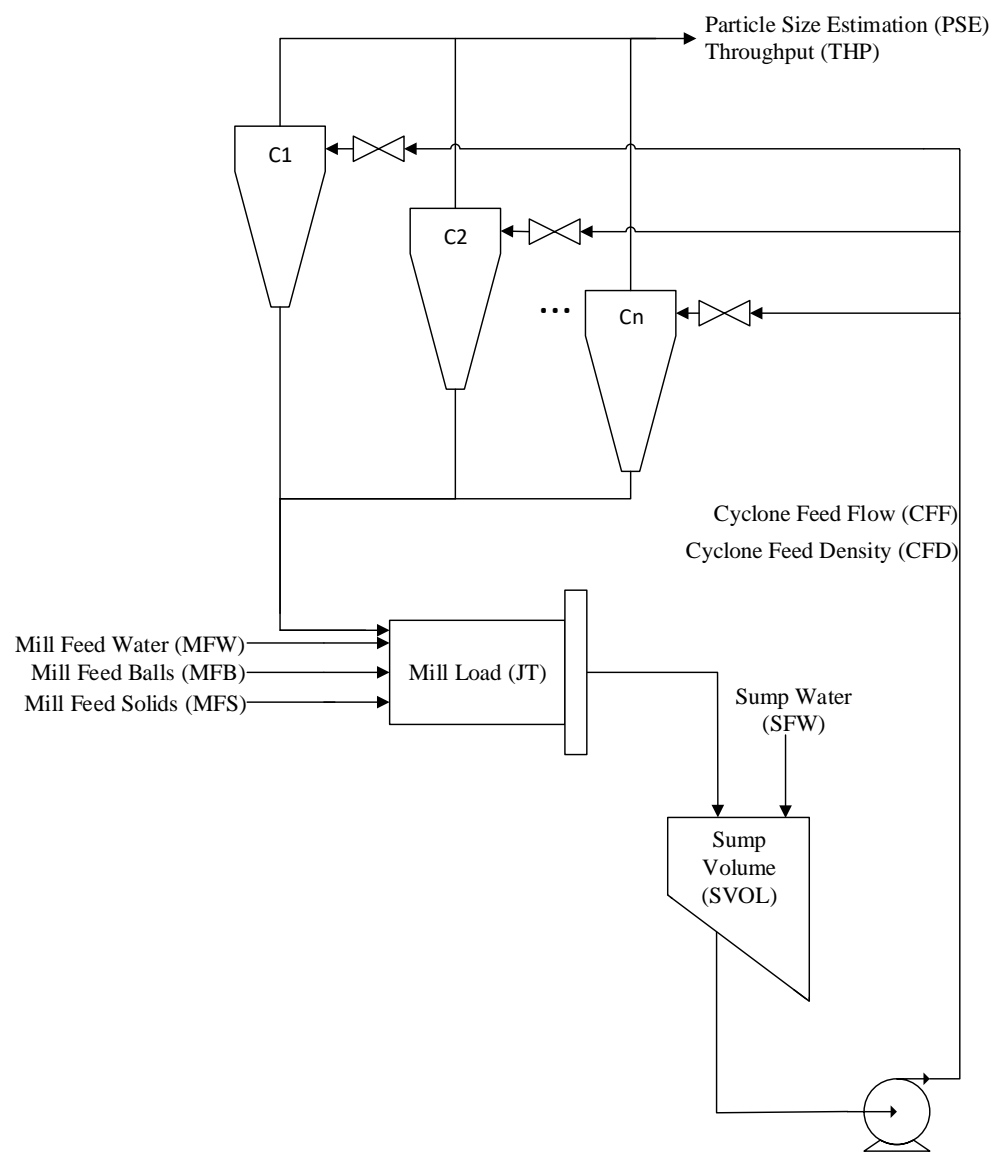

Figure 2: Single stage grinding mill circuit with a hydrocyclone cluster.

To model the material in the circuit, the model uses five states: water, rocks, solids, fines, and balls. It is important to note that although there are three size classes, the model does not have a model state for coarse material, but rather one for solids. The choice not to model coarse ore but rather solids simplify the modelling of the mill and the sump. Table 2 gives a description of each of the symbols and their respective subscripts as used in the model. In Table 2 the variable $V$ denotes volumetric flow-rates in $\mathrm{m}^{3} / \mathrm{h}$ and $X$ denotes the states of the model as volume of material in $\mathrm{m}^{3}$. The first subscript indicates the process unit (mill, sump, cyclone), the second subscript specifies the state (water, balls, rocks, solids, fines), and in the case of flow-rates the third subscript indicates an inflow, outflow, or underflow.

\subsection{Model parameter values and descriptions}

The nomenclature for the grinding mill circuit model is given in Table 3 . The values for the parameters are taken from [1]. 
Table 1: Grinding mill circuit variables

\begin{tabular}{|c|c|c|}
\hline Variable & Description & Unit \\
\hline \multicolumn{3}{|c|}{ Manipulated Variables } \\
\hline$M F W$ & Flow-rate of water to the mill & {$\left[\mathrm{m}^{3} / \mathrm{h}\right]$} \\
\hline$M F O$ & Feed-rate of ore to the mill & {$[\mathrm{t} / \mathrm{h}]$} \\
\hline$M F B$ & Feed-rate of steel balls to the mill & {$[\mathrm{t} / \mathrm{h}]$} \\
\hline$S F W$ & Flow-rate of water to the sump & {$\left[\mathrm{m}^{3} / \mathrm{h}\right]$} \\
\hline$C F F$ & Flow-rate of slurry to the hydrocyclone cluster & {$\left[\mathrm{m}^{3} / \mathrm{h}\right]$} \\
\hline \multicolumn{3}{|c|}{ Controlled Variables } \\
\hline$J_{T}$ & Fraction of the mill volume filled with charge & {$[-]$} \\
\hline SVOL & Volume of slurry in sump & {$\left[\mathrm{m}^{3}\right]$} \\
\hline$P S E$ & Product particle size estimate & {$[-]$} \\
\hline \multicolumn{3}{|c|}{ Measured Variables } \\
\hline$P_{\text {mill }}$ & Power draw of the mill motor & {$[\mathrm{kW}]$} \\
\hline THP & Throughput & {$[\mathrm{t} / \mathrm{h}]$} \\
\hline$C F D$ & Hydrocyclone feed density & {$\left[\mathrm{t} / \mathrm{m}^{3}\right]$} \\
\hline
\end{tabular}

Table 2: Description of subscripts

\begin{tabular}{ll}
\hline Subscript & Description \\
\hline$X_{\Delta-}$ & m-mill; s-sump; c-hydrocyclone cluster; ci-ith hydrocyclone \\
$X_{-\Delta}$ & w-water; s-solids; c-coarse; f-fines; r-rocks; b-balls \\
$V_{--\Delta}$ & i-inflow; o-outflow; u-underflow \\
\hline
\end{tabular}

\subsection{Mill Module}

The mill is modelled by incorporating the effects of mill power draw and slurry rheology in the calculation of the mill load and breakage power functions. The constituents of charge in the milling circuit are represented by five states: rocks $\left(X_{m r}\right)$, solids $\left(X_{m s}\right)$, fines $\left(X_{m f}\right)$, balls $\left(X_{m b}\right)$ and water $\left(X_{m w}\right)$. The model describes the states by considering the inflow, outflow, generation and consumption of each state.

The dynamics of the mill hold-ups are governed by the following state equations,

$$
\begin{aligned}
\dot{X}_{m w} & =V_{m w i}-V_{m w o}+V_{c w u} \\
\dot{X}_{m s} & =V_{m s i}-V_{m s o}+V_{c s u}+R C \\
\dot{X}_{m f} & =V_{m f i}-V_{m f o}+V_{c f u}+F P \\
\dot{X}_{m r} & =V_{m r i}-R C \\
\dot{X}_{m b} & =V_{m b i}-B C
\end{aligned}
$$

where $V_{m w i}, V_{m s i}, V_{m f i}, V_{m r i}$, and $V_{m b i}\left(m^{3} / h\right)$ are the feed rate of water, solids, fines, rocks and balls into the mill respectively; $V_{c w u}, V_{c s u}$, and $V_{c f u}\left(m^{3} / h\right)$ are the flow-rates 
Table 3: Mill model parameters from [1]

\begin{tabular}{ccl}
\hline Parameter & Value & Description \\
\hline$\alpha_{f}$ & 0.055 & Fraction of fines in the feed ore \\
$\alpha_{r}$ & 0.465 & Fraction of rocks in the feed ore \\
$\alpha_{P}$ & 1.0 & $\begin{array}{l}\text { Fractional power reduction per fractional reduction from } \\
\text { maximum mill speed }\end{array}$ \\
$\alpha_{\phi_{f}}$ & 0.01 & $\begin{array}{l}\text { Fractional change in } \mathrm{kW} / \text { fines produced per change in fractional } \\
\text { filling of mill }\end{array}$ \\
$\alpha_{\text {speed }}$ & 0.72 & Fraction of critical mill speed \\
$\delta_{P_{s}}$ & 17.46 & Power-change parameter for fraction of solids in the mill \\
$\delta_{P_{v}}$ & 17.46 & Power-change parameter for volume of mill filled \\
$D_{B}$ & 7.85 & Density of steel balls $\left[\mathrm{t} / \mathrm{m}^{3}\right]$ \\
$D_{S}$ & 3.2 & Density of feed ore $\left[\mathrm{t} / \mathrm{m}^{3}\right]$ \\
$\varepsilon_{s v}$ & 0.6 & Maximum fraction solids by volume of slurry at zero slurry flow \\
$\phi_{b}$ & 90.0 & Steel abrasion factor $[\mathrm{kWh} / \mathrm{t}]$ \\
$\phi_{f}$ & 29.5 & Power needed per tonne of fines produced [kWh/t] \\
$\phi_{r}$ & 6.72 & Rock abrasion factor $[\mathrm{kWh} / \mathrm{t}]$ \\
$\varphi_{P_{\max }}$ & 0.57 & Rheology factor for maximum mill power draw \\
$P_{\max }$ & 1670 & Maximum mill motor power draw $[\mathrm{kW}]$ \\
$v_{\operatorname{mill}}$ & 59.12 & Mill volume $\left[\mathrm{m}^{3}\right]$ \\
$v_{P_{\max }}$ & 0.34 & Fraction of mill volume filled for maximum power draw \\
$V_{V}$ & 88.0 & Volumetric flow per "flowing volume" driving force $\left[\mathrm{h}^{-1}\right]$ \\
\hline
\end{tabular}


of the water, solids and fines at the underflow of the hydrocyclone cluster respectively; $V_{m w o}, V_{m s o}$, and $V_{m f o}\left(m^{3} / h\right)$ are the flow-rates of water, solids from the mill to the sump respectively. $R C, B C$, and $F P\left(m^{3} / h\right)$ represent rock consumption, ball consumption and fines production respectively.

Material is fed to a mill through a feeder module. The input streams into the mill are,

$$
\begin{aligned}
V_{m w i} & =M F W \\
V_{m s i} & =\frac{M F O}{D_{S}}\left(1-\alpha_{r}\right) \\
V_{m f i} & =\frac{M F O}{D_{S}} \alpha_{f} \\
V_{m r i} & =\frac{M F O}{D_{S}} \alpha_{r} \\
V_{m b i} & =\frac{M F B}{D_{B}}
\end{aligned}
$$

where $D_{S}$ and $D_{B}\left(t / m^{3}\right)$ are the densities of the feed ore and the steel balls respectively; parameters $\alpha_{f}$ and $\alpha_{r}$ represent the fraction of fines and rocks in $M F O$ respectively.

The material discharge flow-rates from the mill to the sump are,

$$
\begin{aligned}
V_{m w o} & =V_{V} \varphi X_{m w} \frac{X_{m w}}{X_{m s}+X_{m w}} \\
V_{m s o} & =V_{V} \varphi X_{m w} \frac{X_{m s}}{X_{m s}+X_{m w}} \\
V_{m f o} & =V_{V} \varphi X_{m w} \frac{X_{m f}}{X_{m s}+X_{m w}}
\end{aligned}
$$

where $V_{V}(1 / h)$ is the discharge rate and $\varphi$ is an empirical function called the rheology factor. Parameter $V_{V}$ accounts for the shape and build of the end-discharge screen.

The rheology factor incorporates the effect of the fluidity and density of the slurry in the calculation of the milling circuits performance [33]. A rheology factor of one will indicate the slurry is non-flowing, while a rheology factor of zero is the result of no solids in the slurry and is therefore only water. The rheology factor is calculated as,

$$
\varphi=\left(\max \left[0,\left(1-\left(\frac{1}{\varepsilon_{s v}}-1\right) \frac{X_{m s}}{X_{m w}}\right)\right]\right)^{0.5}
$$

where $\varepsilon_{s v}$ is the fraction of solids in the slurry that will result in no flow.

The material consumption and generation equations are, 


$$
\begin{aligned}
R C & =\frac{P_{\text {mill }} \varphi}{D_{S} \phi_{r}}\left(\frac{X_{m r}}{X_{m r}+X_{m s}}\right) \\
F P & =\frac{P_{\text {mill }}}{D_{S} \phi_{f}}\left[1+\alpha_{\phi_{f}}\left(\frac{X_{m w}+X_{m r}+X_{m s}+X_{m b}}{v_{\text {mill }}}-v_{P_{\text {max }}}\right)\right]^{-1} \\
B C & =\frac{P_{\text {mill }} \varphi}{\phi_{b}}\left(\frac{X_{m b}}{D_{S}\left(X_{m r}+X_{m s}\right)+D_{B} X_{m b}}\right)
\end{aligned}
$$

where $P_{\text {mill }}(k W)$ is the power draw of the mill, $\phi_{b}$ and $\phi_{r}(k W h / t)$ are the abrasion factors of balls and rocks, $\phi_{f}(k W h / t)$ is the power needed per tonne of fines produced, $\alpha_{\phi_{f}}$ is the fractional change in $\phi_{f}$ as a result of the mill filling and $v_{P_{\max }}$ is the maximum mill filling for maximum power draw. Small steel particles resulting from steel ball wear will exit the mill as part of the solids of the mill. However, since the breakage is slow compared to the breakage of solids, it has a negligible dynamic effect on $X_{m s}$. The fine steel particles will eventually form part of the gangue in downstream units.

The fraction of the mill filled is a critical controlled variable $(\mathrm{CV})$ to ensure stable operation of the grinding mill circuit. The load of the mill is calculated as,

$$
J_{T}=\frac{X_{m w}+X_{m s}+X_{m r}+X_{m b}}{v_{m i l l}}
$$

where $v_{\text {mill }}\left(\mathrm{m}^{3}\right)$ is the volumetric size of the mill. The power draw of the mill is defined as,

$$
P_{\text {mill }}=P_{\max }\left\{1-\delta_{P v} Z_{x}^{2}-\delta_{P s} Z_{r}^{2}\right\} \cdot\left(\alpha_{\text {speed }}\right)^{\alpha_{P}}
$$

where $P_{\max }(k W)$ is the maximum mill power draw, $\alpha_{\text {speed }}$ is the fraction of critical mill speed, $\alpha_{P}$ is the fractional change in mill power draw due to a change in $\alpha_{\text {speed }}, \delta_{P v}$ and $\delta_{P s}$ are parameters estimating power draw change due to the volume of the mill filled and fraction of solids in the mill respectively. The effect of the total charge on mill power is modelled by the empirical definition of

$$
Z_{x}=\frac{J_{T}}{\varphi_{P_{\max }}}-1
$$

and the effect of the solids content on the mill power is modelled by the empirical definition of

$$
Z_{r}=\frac{\varphi}{\varphi_{P \max }}-1,
$$

where $\varphi_{P_{\max }}$ is the rheology factor at maximum mill power draw.

\subsection{Sump Module}

Because of the end-discharge screen of the mill which prevents rocks and balls from exiting the mill, the sump will not have any steel balls or rocks. The sump states are: water 
$\left(X_{s w}\right)$, solids $\left(X_{s s}\right)$, and fines $\left(X_{s f}\right)$. The dynamics of the sump hold-ups are governed by the following state equations,

$$
\begin{aligned}
\dot{X}_{s w} & =V_{m w o}-V_{s w o}+S F W \\
\dot{X}_{s s} & =V_{m s o}-V_{s s o} \\
\dot{X}_{s f} & =V_{m f o}-V_{s f o}
\end{aligned}
$$

where $V_{\text {swo }}, V_{\text {sso }}$ and $V_{\text {sfo }}\left(\mathrm{m}^{3} / h\right)$ are the sump discharge flow-rates of water, solids and fines respectively. It is assumed the slurry in the sump is fully mixed. The discharge of each state from the sump through the variable speed pump is defined as,

$$
\begin{aligned}
V_{s w o} & =C F F \frac{X_{s w}}{X_{s w}+X_{s s}} \\
V_{s s o} & =C F F \frac{X_{s s}}{X_{s w}+X_{s s}} \\
V_{s f o} & =C F F \frac{X_{s f}}{X_{s w}+X_{s s}} .
\end{aligned}
$$

The volume of the slurry in the sump, SVOL $\left(\mathrm{m}^{3}\right)$, is controlled to ensure the sump does not run dry or overflows. The hydrocyclone feed density, $C F D\left(t / m^{3}\right)$, is manipulated by the feed rate of water to the sump, $S F W\left(\mathrm{~m}^{3} / h\right)$. In this study, $C F D$ is not directly controlled, but minimized where possible in order to maximise circulating load and increase classifier performance [23]. The two output variables are modelled as,

$$
\begin{aligned}
S V O L & =X_{s s}+X_{s w} \\
C F D & =\frac{X_{s w}+X_{s s} D_{s}}{X_{s w}+X_{s s}} .
\end{aligned}
$$

\subsection{Hydrocyclone cluster model}

A hybrid model is a model that incorporates continuous and discrete time dynamics [34]. A grinding mill circuit that contains a cluster of hydrocyclones can be represented by a hybrid model with the switching in and out of hydrocyclones making up the discrete dynamics [35]. Such circuits are often controlled using a layered approach, with a bottom layer controlling the continuous dynamics of the mill and sump, and a top layer controlling the switching of individual cyclones in the cluster [36]. By incorporating the continuous and switching dynamics in one model an advanced hybrid controller is able to consider all CVs in the circuit to ensure optimal operation of the process [37].

Hybrid models are often modelled as Mixed Logical Dynamical (MLD) models. Such models make it relatively simple to formulate a hybrid controller, and special software packages such as HYSDEL can automatically convert the controller objective function to a set of linear inequalities that are used to solve the control problem [25, 38].

In this study the complete non-linear hybrid model is considered for the controller design and simulation. The complete hybrid non-linear state space model containing the continuous dynamics of the mill, sump, and hydrocyclones, and the discrete dynamics of the 
hydrocyclone activation variables takes the common form of

$$
\begin{array}{ll}
\dot{\mathbf{x}}= & \mathbf{f}(t, \mathbf{x}, \mathbf{u}, \rho) \\
\mathbf{y}= & \mathbf{h}(t, \mathbf{x}, \mathbf{u}, \rho) \\
\text { with } & \\
\mathbf{x} & \in \mathbb{R} \\
\mathbf{u} & \in \mathbb{R} \\
\mathbf{y} & \in \mathbb{R} \\
\rho & \in\{1,0\},
\end{array}
$$

where $\mathbf{x}, \mathbf{y}$, and $\mathbf{u}$ represents the plant's state, measured, and manipulated variables respectively. The activation signals for the individual cyclones in the hydrocyclone cluster are contained in $\rho$. The variables are given by,

$$
\begin{aligned}
& \mathbf{x}=\left[X_{m w}, X_{m s}, X_{m f}, X_{m r}, X_{m b}, X_{s w}, X_{s s}, X_{s f}\right]^{T} \\
& \mathbf{u}=[M F O, M F W, M F B, S F W, C F F]^{T} \\
& \mathbf{y}=\left[J_{T}, P_{\text {mill }}, S V O L, C F D, P S E, T H P\right]^{T} .
\end{aligned}
$$

Function $\mathbf{f}$ is given by (1) and (12), and function $\mathbf{h}$ is given by (8), (9), (14), and (22). The vector $\rho$ consists of all the activation variables for each hydrocyclone $\rho_{i}$ where $i$ is used to indicate a specific hydrocyclone, i.e.

$$
\begin{gathered}
\rho_{i}= \begin{cases}1 & \text { if hydrocyclone ON } \\
0 & \text { if hydrocyclone OFF }\end{cases} \\
i=1,2,3 \ldots, N_{\text {cyclones }},
\end{gathered}
$$

where $N_{\text {cyclones }}$ is the total number of hydrocyclones in the cluster. The number of active cyclones in the cluster is defined as,

$$
N_{\text {ActiveCyclones }}=\sum_{n=1}^{N_{\text {cyclones }}} \rho_{i} .
$$

The hydrocyclone modelled in [1] is represented as a set of static non-linear volumetric flow-rate equations based on the Plitt hydrocyclone model. Similar to the Plitt model, the model is based on the assumption that the corrected classification size is exponentially proportional to the fraction of solids in the total inflow volume, inversely proportional to the total cyclone feed flow and can be modelled independent of feed size characteristics [39]. Although these are simplifying assumptions, the aim is not necessarily to be quantitatively accurate but to be qualitatively accurate. The minimum requirement for controller design is a model with responses in the correct directions [32].

The non-linear hydrocyclone cluster model is formulated by assuming identical cyclones that can be switched on or off using activation variables. Since identical hydrocyclones are used, it is assumed the parameters for each hydrocyclone will be the same. Also, since the 
cut of the cyclone is assumed independent of the feed size, the cyclone parameters are not influenced by the small set of size classes.

Flow-rates at the underflow of each $i$-th hydrocyclone are calculated as

$$
\begin{aligned}
C F F_{i} & =\frac{C F F}{\sum_{n=1}^{N_{\text {cyclones }}} \rho_{i}} \\
V_{\text {cicu }} & =\rho_{i} \frac{C F F_{i}\left(X_{s s}-X_{s f}\right)}{X_{s w}+X_{s s}}\left(1-C_{1} \exp \left(\frac{-C F F_{i}}{\varepsilon_{c}}\right)\right)\left(1-\left(\frac{F_{i}}{C_{2}}\right)^{C_{3}}\right)\left(1-P_{i}^{C_{4}}\right) \\
V_{\text {ciwu }} & =\rho_{i} \frac{X_{s w}\left(V_{\text {cicu }}-F_{u i} V_{\text {cicu }}\right)}{F_{u i} X_{\text {sw }}+F_{u i} X_{s f}-X_{s f}} \\
V_{\text {cifu }} & =\rho_{i} \frac{X_{s f}\left(V_{\text {cicu }}-F_{u i} V_{\text {cicu }}\right)}{F_{u i} X_{\text {sw }}+F_{u i} X_{s f}-X_{s f}} \\
V_{\text {cisu }} & =V_{\text {cicu }}+V_{\text {cifu }}
\end{aligned}
$$

where $C F F_{i}\left(m^{3} / h\right)$ refers to the hydrocyclone feed for each individual hydrocyclone; $V_{\text {cicu }}$, $V_{\text {ciwu }}, V_{\text {cifu }}$, and $V_{\text {cisu }}\left(\mathrm{m}^{3} / \mathrm{h}\right)$ are the underflow of coarse ore, water, fines and solids for the $i$-th hydrocyclone respectively; $F_{i}=V_{s s o} / C F F$ is the fraction of solids in the cyclone feed; $P_{i}=V_{s f o} / V_{s s o}$ is the fraction fines in the feed solids; $\varepsilon_{c}\left(\mathrm{~m}^{3} / h\right)$ relates to the coarse split; $C_{1}$ relates to the split at low-flows when the centrifugal force on particles is small; $C_{2}$ normalizes the fraction solids in the feed according to maximum packing fraction of solid particles; and $C_{3}$ and $C_{4}$ adjusts the sharpness of the dependency on $F_{i}$ and $P_{i}$. The fraction of solids in the underflow volume for each hydrocyclone is,

$$
F_{u i}=0.6-\left(0.6-\frac{X_{s s}}{X_{s w}+X_{s s}}\right) \exp \left(\frac{-V_{c i c u}}{\alpha_{s u} \varepsilon_{c}}\right)
$$

where $\alpha_{s u}$ relates to the fraction solids in the underflow, and the constant factor 0.6 is related to the maximum packing fraction of material [40].

The total underflow recycled to the mill is the summation of all the underflow streams. The flow-rates at the overflow of each hydrocyclone are,

$$
\begin{aligned}
V_{\text {ciso }} & =\rho_{i} \frac{C F F_{i} X_{s s}}{X_{s s}+X_{s w}}+\rho_{i} \frac{X_{s f}\left(V_{c i c u}-F_{u n} V_{c i c u}\right)}{F_{u i} X_{s w}+F_{u i} X_{s f}-X_{s f}}-V_{c i c u} \\
V_{c i f o} & =\rho_{i} \frac{C F F_{i} X_{s f}}{X_{s s}+X_{s w}}-\rho_{i} \frac{X_{s f}\left(V_{c i c u}-F_{u i} V_{c i c u}\right)}{F_{u i} X_{s w}+F_{u i} X_{s f}-X_{s f}} \\
V_{\text {ciwo }} & =\rho_{i} \frac{C F F_{i} X_{s w}}{X_{s s}+X_{s w}}-V_{c i w u} .
\end{aligned}
$$

The total overflow of solids, fines and water for the hydrocyclone cluster is the summation of all the individual overflows of solids, fines and water respectively. The grinding mill circuit 
Table 4: Hydrocyclone parameters

\begin{tabular}{ccl}
\hline Parm & Value & Description \\
\hline$\alpha_{s u}$ & 0.915 & $\begin{array}{l}\text { Parameter related to fraction solids in } \\
\text { underflow }\end{array}$ \\
$C_{1}$ & 0.6 & Constant \\
$C_{2}$ & 0.7 & Constant \\
$C_{3}$ & 4.0 & Constant \\
$C_{4}$ & 4.0 & Constant \\
$\varepsilon_{c}$ & 15.867 & Parameter related to coarse split $\left[\mathrm{m}^{3} / \mathrm{h}\right]$ \\
\hline
\end{tabular}

throughput $(T H P)$ and quality $(P S E)$ is calculated as,

$$
\begin{aligned}
V_{\text {cfo }} & =\sum_{i=1}^{N_{\text {cyclones }}} V_{\text {cifo }} \\
V_{\text {cso }} & =\sum_{i=1}^{N_{\text {cyclones }}} V_{\text {ciso }} \\
P S E & =\frac{V_{\text {cfo }}}{V_{\text {cso }}} \\
T H P & =V_{\text {cso }} D_{s},
\end{aligned}
$$

where $V_{c f o}$ and $V_{c s o}\left(m^{3} / h\right)$ are the overflow flow-rates of fines and solids respectively for the cluster as a whole.

In this study the single hydrocyclone in [1] is replaced with a cluster of 9 hydrocyclones, with a nominal operating value of 8 hydrocyclones. A minimum of 6 cyclones must always be active. The individual hydrocyclone parameters were refitted in this study to produce similar steady-state results as in [1].

It was found that the dimensionless parameters $C_{1}, C_{2}, C_{3}, C_{4}$ and $\alpha_{s u}$ are not influenced by a change in the nominal flow of the hydrocyclone. Consequently, only $\varepsilon_{c}$ needed to be refitted from the data provided in [1] in order to use a cluster of 8 hydrocyclones at nominal conditions rather than one. The total coarse split for the survey data in [1] was $V_{c c u} / V_{c c i}=0.967$. This can also be expressed as,

$$
\frac{V_{c c u}}{V_{c c i}}=1-C_{1} e^{\frac{-C F F}{\varepsilon_{c}}} .
$$

For identical cyclones, each individual coarse split should be equal to the total coarse split. Therefore, $C F F_{i}=46.75 \mathrm{~m}^{3} / \mathrm{h}$ at nominal flow can be used to calculate $\varepsilon_{c}$ for the hydrocyclones in the cluster. The nomenclature for the hydrocyclone cluster is given in Table 4.

\section{Controller design}

Two controller scenarios are simulated and the results compared: 
A base case NMPC controller where the number of active cyclones remain constant, i.e. there are no discrete dynamics. The available MVs and CVs are:

$$
\begin{aligned}
& u=[M F O, S F W, C F F]^{T} \\
& y=\left[J_{T}, S V O L, P S E\right]^{T}
\end{aligned}
$$

An HNMPC controller where the number of active cyclones can be increased or decreased. The available MVs and CVs are:

$$
\begin{aligned}
& u=\left[M F O, S F W, C F F, N_{\text {ActiveCyclones }}\right]^{T} \\
& y=\left[J_{T}, S V O L, P S E\right]^{T}
\end{aligned}
$$

In (24) and (25) the vector $u$ contains the MVs and the vector $y$ contains the CVs. As discussed in Section 3, the grinding mill circuit also has $M F W$ and $M F B$ as process inputs. However, they are not considered in the formulation of the control problem. $M F W$ is kept at a constant ratio to $M F O$, and $M F B$ is kept constant.

\subsection{Controller designs}

The aim of both controllers are formulated using a receding horizon control approach [22]:

$$
\begin{gathered}
\quad \min _{u_{k}, \cdots, u_{k+N_{c}-1}} J\left(u_{k}, \cdots, u_{k+N_{c}-1}, x_{k}\right) \\
\text { s.t. } x_{k+1}=f\left(x_{k}, u_{k}\right) \\
y_{k}=h\left(x_{k}, u_{k}\right) \\
u_{l} \leq u_{k} \leq u_{u} \\
y_{l} \leq y_{k} \leq y_{u}
\end{gathered}
$$

where $u_{l}$ and $u_{u}$ represent the lower and upper limits of the MVs respectively, and $y_{l}$ and $y_{u}$ represent the lower and upper limits of the CVs respectively. $f$ and $h$ are the discretised models of (15). The initial states are given in Table 5 and the initial conditions and operating limits for the CVs and MVs are given in Table 6. For this study $J_{T}$ and PSE are controlled at setpoint, while $S V O L$ is controlled in a range between low and high soft-limits.

The performance function, $J$, penalises large changes in MV moves, as well as any deviations between the CVs and their setpoints or deviations beyond the soft limits. The performance function is adapted from [20] and is given as,

$$
\begin{aligned}
J(\cdot)= & \sum_{n=0}^{N_{p}-1}\left[\left(y_{k+n \mid k}^{r}-\hat{y}_{k+n \mid k}\right)^{T} Q_{r}\left(y_{k+n \mid k}^{r}-\hat{y}_{k+n \mid k}\right)+S_{k+n \mid k} Q_{s} S_{k+n \mid k}\right] \\
& +\sum_{n=0}^{N_{c}-1} \Delta u_{k+i \mid k}{ }^{T} R \Delta u_{k+i \mid k}
\end{aligned}
$$

where $y^{r}$ is the $\mathrm{CV}$ setpoint, $\hat{y}$ is the predicted output, matrices $Q_{r}, Q_{s}$ and $R$ are the weighting matrices for setpoint tracking, slack variables and control action respectively, and 
$N_{c}$ and $N_{p}$ are the control and prediction horizons respectively. The slack variable $S_{n}$ is defined as,

$$
S_{n}= \begin{cases}y_{n}-y_{s h} & ; y_{n}>y_{s h} \\ y_{n}-y_{s l} & ; y_{n}<y_{s l} \\ 0 & ; y_{s l} \leq y_{n} \leq y_{s h}\end{cases}
$$

where $y_{s h}$ and $y_{s l}$ are the soft high and low limits. A soft limit is used for a variable controlled in a range where the range is still well within the hard constraints of the variable. Therefore, if a soft limit is violated the controller will control the violation the same as a set-point deviation and will not regard it as an infeasible solution (which is the case when a hard constraint is reached).

The objective function is formulated such that the energy in the MVs is minimised, i.e. the objective function penalizes large MV moves such that minimum energy is expended to reach the control objective. Although energy in the form of $P_{\text {mill }}$ can be included in the objective function explicitly, it falls outside the scope of this study.

Full-state feedback is assumed for both controllers with added state noise of $2 \%$. Fullstate feedback is a significant assumption as the measurements available in industrial grinding mill circuits are limited [11]. In Fig. 1 the model states are estimated from the process measurements. Therefore, full-state feedback assumes that the five mill states and three sump states can be measured directly or estimated from available measurements.

Although various state estimators have been investigated for grinding mills [31, 41, 42, $43]$, it remains a challenge to estimate mill hold-ups $[17,44]$. In the aforementioned state estimators the states could be estimated with an average state error of less than $2 \%$. Due to the accuracy of these state estimators an assumption to use $2 \%$ state noise is sufficient considering that if the state estimator is added to the control loop, the controller will still perform as it did in this study. It is assumed that all of the base-layer actuator control loops are ideal. Model-plant mismatch (as in [45]) is not considered in this study. It is assumed that the process model is an accurate reflection of the plant.

Table 5: Initial states used by NMPC and HNMPC

\begin{tabular}{lcc}
\hline State & Initial Value & Unit \\
\hline$X_{m w}$ & 4.6295 & {$\left[\mathrm{~m}^{3}\right]$} \\
$X_{m s}$ & 4.6533 & {$\left[\mathrm{~m}^{3}\right]$} \\
$X_{m f}$ & 0.9611 & {$\left[\mathrm{~m}^{3}\right]$} \\
$X_{m r}$ & 1.9946 & {$\left[\mathrm{~m}^{3}\right]$} \\
$X_{m b}$ & 8.2321 & {$\left[\mathrm{~m}^{3}\right]$} \\
$X_{s w}$ & 6.8636 & {$\left[\mathrm{~m}^{3}\right]$} \\
$X_{s s}$ & 3.1364 & {$\left[\mathrm{~m}^{3}\right]$} \\
$X_{s f}$ & 0.6478 & {$\left[\mathrm{~m}^{3}\right]$} \\
\hline
\end{tabular}


Table 6: Initial conditions and operating limits used by NMPC and HNMPC

\begin{tabular}{lcccl}
\hline Variable & Initial Value & Min & Max & Unit \\
\hline Manipulated Variables & & & \\
$M F O$ & 65 & 0 & 200 & {$[\mathrm{t} / \mathrm{h}]$} \\
$S F W$ & 140.47 & 0 & 300 & {$\left[\mathrm{~m}^{3} / \mathrm{h}\right]$} \\
$C F F$ & 374 & 200 & 450 & {$\left[\mathrm{~m}^{3} / \mathrm{h}\right]$} \\
Controlled Variables & & & \\
$J_{T}$ & 0.33 & 0.2 & 0.4 & {$[-]$} \\
$S V O L$ & 10 & 2.5 & 38 & {$\left[\mathrm{~m}^{3}\right]$} \\
$P S E$ & 0.67 & 0.5 & 0.8 & {$[-]$} \\
\hline
\end{tabular}

\subsubsection{Controller weights}

For the controller set-up the strongest emphasis is placed on achieving the PSE setpoint. Maintaining $P S E$ is important for successful concentration of valuable materials in the downstream processes and is a key performance indicator that should be tightly controlled. The $Q_{r}$ and $Q_{s}$ weighting matrices were formulated by ensuring that when $P S E$ or $J_{T}$ deviates from the setpoint by $1 \%$, the effect on the cost function will be the same as when $S V O L$ deviates $5 \%$ from its soft limits. This ensures that the controller will be equally aggressive in bringing $P S E$ and $J_{T}$ back to setpoint, but less aggressive with $S V O L$. Mathematically this can be represented as,

$$
Q_{r 1}\left(1 \% J T_{S P}\right)^{2}=Q_{r 2}\left(1 \% P S E_{S P}\right)^{2}=Q_{s}\left(5 \% S V O L_{s l}\right)^{2} .
$$

The setpoints for $J_{T}$ and $P S E$ are taken as the initial steady-state conditions in Table 6 . The soft limits for $S V O L$ are chosen within the hard constraints in Table 6 . The lower soft limit $\left(S V O L_{s l}\right)$ is chosen as $10 \mathrm{~m}^{3}$ (which is also the starting condition of the simulation) and the upper soft limit $\left(S V O L_{s u}\right)$ is chosen as $35 \mathrm{~m}^{3}$. These chosen values allow a big enough safety margin between the soft high and low and the absolute high and low limits for the sump.

Similarly, the $R$ weighting matrix for the input variables was determined such that $1 \%$ changes of half the ranges of $C F F, M F O$ and $S F W$ will produce the same error in the cost function,

$$
R_{1}\left(\frac{1 \% M F O_{\text {range }}}{2}\right)^{2}=R_{2}\left(\frac{1 \% S F W_{\text {range }}}{2}\right)^{2}=R_{3}\left(\frac{1 \% C F F_{\text {range }}}{2}\right)^{2} .
$$

The $R$ matrix was scaled to produce $1 \%$ of the error compared to the $Q$ matrix, or mathematically,

$$
R_{1}\left(\frac{1 \% M F O_{\text {range }}}{2}\right)^{2}=0.01 Q_{r 1}\left(1 \% J T_{S P}\right)^{2}
$$

By choosing $Q_{s}=10$, the weighting matrices are calculated from (29) by using the initial 
simulation setpoints from Table 6 as,

$$
Q_{r}=10^{3}\left[\begin{array}{cc}
230 & 0 \\
0 & 55.7
\end{array}\right]
$$

and by using the result from (32) and the ranges in Table 6 with the relation in (31) the $R$ weighting matrix can be calculated as,

$$
R=\left[\begin{array}{ccc}
0.025 & 0 & 0 \\
0 & 0.0111 & 0 \\
0 & 0 & 0.0082
\end{array}\right]
$$

\subsubsection{Prediction and Control Horizons}

The prediction horizon, $N_{p}$, should generally be chosen such that the longest settling time for all of the outputs are observed [21]. Since the mill and sump act as integrators, this is impractical and therefore a trial and error approach was followed. For a sampling time of $T_{s}=10 \mathrm{~s}$, the prediction horizon resulting in the best results was $N_{p}=36$ (6 minutes). The control horizon was chosen as half of the prediction horizon $N_{c}=18$ (3 minutes).

\section{2. $N M P C$ implementation}

The cost function was minimized using the fmincon function with the Sequential Quadratic Programming $(s q p)$ algorithm in MATLAB ${ }^{1}$ to solve the values for the three MVs. The optimiser propagates the grinding mill model as presented in Section 3 using a 4th order Runge-Kutta algorithm.

\subsection{HNMPC implementation}

The grinding mill circuit with a hydrocyclone cluster contains hybrid dynamics and therefore requires a solver that can calculate the control moves while handling the nonlinearities as well as the discontinuities caused by the switching of hydrocyclones.

In $[25,46]$ the HMPC controller used particle swarm optimisation (PSO) to solve the objective function. In [25] PSO was successfully implemented on a linear system, however in [46] they showed that for the PSO to handle non-linearities the algorithm needs to be adapted in order to ensure that a global minimum is found, and not just a local minimum.

The genetic algorithm (GA) is a solver that has shown advantage over solvers such as PSO because of its ability to accommodate strong non-linearities, large variations in initial "guess" inputs, mixed integer dynamics (with various switching components) and convergence to a global minimum in the presence of many local minima [26, 47]. The GA is used as the solver in this paper because of these advantages.

The genetic algorithm calculates a set of solutions called the population. The population aims to minimise the GA fitness function within constraints. The first GA iteration uses the

\footnotetext{
${ }^{1}$ MATLAB is a registered trademark of The MathWorks Inc.
} 
initial population to generate a new population through a mutation function. The mutation uses the best fit variable values in the population and then discards the other variable values and defines new values based on a stochastic function. The process is repeated until the minimum fitness function value is reached, or the maximum number of generations is exceeded [48].

The Matlab ga function was used to implement the genetic algorithm to form the hybrid non-linear model predictive control (HNMPC) solution. The most important hyperparameters for the $g a$ function is the fitness limit, tolerance, maximum number of generations and population size.

The fitness limit and fitness tolerance were chosen based on the influences of the CVs on the objective function. The default value of the fitness limit is negative infinity, and it was altered to 0.1 to ensure that even if there is a small controller offset on the process outputs, the solver will terminate instead of executing until it reaches the maximum number of generations. It is possible to calculate a fitness limit directly from the objective function by substituting in the nominal CV values, allowed setpoint offsets and assuming no changes in MVs. However, this method can become complex since the error is not inherently distributed between the CVs and the controller could produce infeasible solutions where two CVs are at setpoint, and one has an offset more than the allowed error. The fitness tolerance was chosen as $10 \%$ of the fitness limit. In abnormal situations the CVs might not get to setpoint, and if only a local limit is possible, then the solver should also terminate if the objective function value can no longer be decreased by more than the fitness tolerance.

The maximum number of generations and population size has to be chosen in an iterative manner. In a case where the desired operating region cannot be achieved over the prediction horizon, the solver will execute until the maximum number of generations is reached. The population size is the number of parallel attempts at minimising the objective function per generation. Firstly the maximum number of generations was left at the default value, and a suitable value was chosen for the population size by reducing the value until a point is reached where the controller performance deteriorates. Thereafter the maximum number of generations was chosen by forcing the solver to run to the maximum number of iterations and then ensuring that the solver execution time is $20 \%$ less than the controller execution interval time. If at this stage no controller performance degradation is observed, the number of allowed generations is systematically reduced while monitoring controller performance.

The hyper-parameters for the $g a$ function are therefore:

- The fitness function is the non-linear quadratic objective function in (27).

- The fitness limit is 0.1 and the fitness tolerance is 0.01 .

- The maximum number of generations is 20 with a population size of 25 .

- There are 55 variables to solve during each iteration: $3 \mathrm{MVs}$ times the control horizon of 18 , plus the integer value $N_{\text {ActiveCyclones }}$ indicating the number of active cyclones over the prediction horizon. 
The number of active hydrocyclones is included in the HNMPC controller as one variable over the prediction horizon. The state of each individual hydrocyclone is given as an activation variable $\rho_{i}$ in (17). Instead of the HNMPC solving 9 discrete variables $\rho_{i}$ for each hydrocyclone where each variable has a value of one or zero, it rather solves one integer variable $N_{\text {ActiveCyclones. }}$. This approach reduces the computational time for the control moves and will remain valid as long as identical hydrocyclones are used. Additionally, the switching of hydrocyclones has a large dynamic influence on the plant, and in order to avoid sporadic switching leading to plant instability, hydrocyclones can only be switched once per prediction horizon. In other words continuous control moves are made at every execution interval over the control horizon, while hydrocyclone switching can only be done once. This ensures that after a switching event occurred a new one will only take place again after 6 minutes.

Once $N_{\text {ActiveCyclones }}$ is solved, it is converted to a vector to use in the model to assign values for each value of $\rho_{i}$. The limits will therefore be,

$$
5<N_{\text {ActiveCyclones }}<10
$$

The $C F F$ constraint in Table 6 is the total feed to the hydrocyclone cluster at nominal conditions (i.e. 8 active cyclones). Therefore, when the hydrocyclones in the cluster are switched the constraint for $C F F$ changes to,

$$
200 \frac{N_{\text {ActiveCyclones }}}{8} \leq C F F \leq 450 \frac{N_{\text {ActiveCyclones }}}{8}
$$

The number of active cyclones does not influence the constraints for the feed to the mill, or the flow rate of water to the sump.

The constraints on all MVs were added directly in the ga function as hard constraints, ensuring a feasible solution in all operating conditions.

\section{Simulation Results and Discussion}

\subsection{Simulation Scenario}

The aim of the simulation is to disturb the plant (initially at steady-state), and observe how the NMPC and HNMPC controllers react to the upset. The grinding mill circuit was simulated for both controllers with the following general conditions:

- Simulation time of $T_{f}=3.5 \mathrm{~h}$ and a sampling rate of $T_{s}=10 \mathrm{~s}$.

- The mill inlet water $M F W$ is kept at a constant $7 \%$ of $M F O$ and the feed rate of balls into the mill $M F B$ is kept at a constant $5.68 \mathrm{t} / \mathrm{h}$.

- The plant configuration is the same for both controllers, however NMPC only has 8 active cyclones, and the HNMPC can switch between 6 and 9 active cyclones.

- $2 \%$ random state noise was added to all the mill and sump states at each iteration. 
- A disturbance in the hardness of the ore is simulated at $t=12$ min by increasing $\phi_{f}$ to $36.87 \mathrm{kWh} / \mathrm{t}$ and $\phi_{r}$ to $8.4 \mathrm{kWh} / \mathrm{t}$ from their nominal values of $29.5 \mathrm{kWh} / \mathrm{t}$ and 6.72 $\mathrm{kWh} / \mathrm{t}$ respectively. A further hardness disturbance is simulated at $t=107 \mathrm{~min}$ by decreasing $\phi_{f}$ from $36.87 \mathrm{kwh} / \mathrm{t}$ to $19.2 \mathrm{kWh} / \mathrm{t}$ and $\phi_{r}$ from $6.72 \mathrm{kWh} / \mathrm{t}$ to $4.4 \mathrm{kWh} / \mathrm{t}$.

- A disturbance in the mill feed size distribution is simulated by increasing $\alpha_{r}$ to 0.765 from its nominal value of 0.465 at $t=180 \mathrm{~min}$, and then down to 0.365 at $t=195$ min.

- The CV $J_{T}$ is kept constant at its nominal value of 0.33 throughout the simulation.

- The CV SVOL is allowed to drift between $10 \mathrm{~m}^{3}$ and $35 \mathrm{~m}^{3}$, but should be controlled back to the operating region if the soft limits are violated.

- The CV PSE is stepped from its nominal value of 0.67 to 0.73 at $t=30 \mathrm{~min}$, and to 0.64 at $t=145 \mathrm{~min}$.

These disturbances correspond to a case where a stockpile change results in large variances in ore hardness until the feed stabilises. It also creates a scenario where the product quality goes off-specification unless some advanced regulatory control is installed or operators intervene.

The disturbances are simulated using discrete value changes to the simulation model parameters. This means the disturbance will take effect on the mill feed, the breakage rates of the current mill load and circulating load. To simulate a mixture of the old and new feed hardness, the variable could be changed using a first order reaction curve. However, in this study a first order change in hardness (as opposed to the step) showed no noticeable influence on the controller response, and the discrete step made the interpretation of results simpler.

\subsection{Controller performance metrics}

The performance of the controllers need to be quantified in order to evaluate and compare them. This section provides the metrics used to quantify the performance of the economic variables $(P S E$ and $T H P)$ as well as the setpoint control of $J_{T}$. The deviation from setpoint for $P S E$ and $J_{T}$ is quantified by calculating the sum of all squared errors (similar to [4]),

$$
\begin{aligned}
P S E_{\text {Performance }} & =\sum_{k=0}^{N_{f}}\left(P S E^{r}(k)-P S E(k)\right)^{2} \\
J_{\text {Tperformance }} & =\sum_{k=0}^{N_{f}}\left(J_{T}^{r}(k)-J_{T}(k)\right)^{2},
\end{aligned}
$$

where $P S E^{r}$ is the $P S E$ setpoint and $J_{T}^{r}$ is the $J_{T}$ setpoint.The average throughput for the duration of the simulation is calculated as,

$$
\text { THP } P_{\text {Average }}=\frac{1}{N_{f}} \sum_{k=0}^{N_{f}} T H P(k)
$$



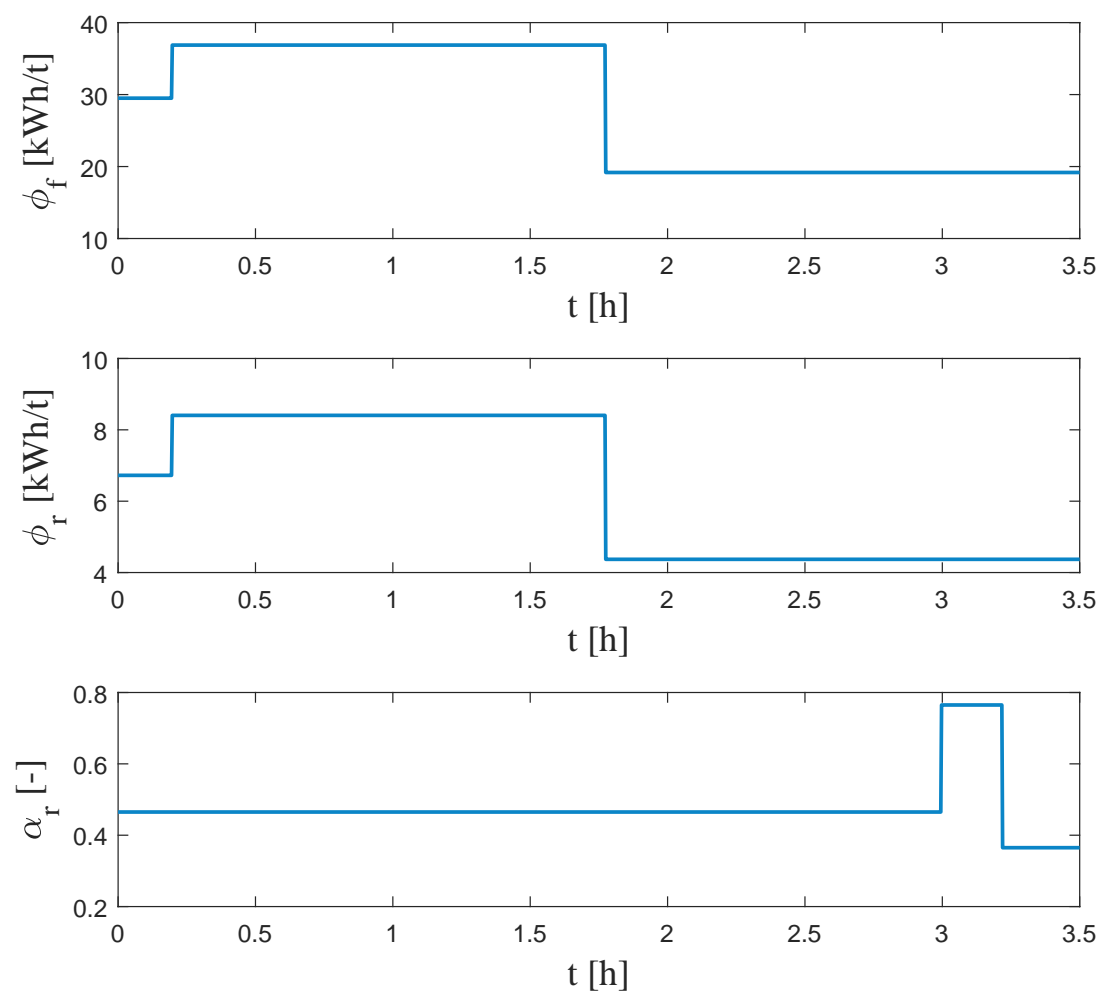

Figure 3: Simulation disturbances. Top: Power needed per tonne of fines produced $\phi_{f}$. Middle: Rock abrasion factor $\phi_{r}$. Bottom: Fraction of rocks in the feed $\alpha_{r}$.

\subsection{Results}

The disturbances added to the simulation are shown in Fig. 3. A summary for the performance metrics of $P S E, J_{T}$ and average throughput is given in Table 7 . This summary of results show that both controllers could control $J_{T}$ well. The HNMPC was capable of maintaining the PSE setpoint with a $50 \%$ reduction in error during the disturbances compared to the NMPC. An average throughput increase of $4.8 \%$ was observed for the HNMPC controller for the duration of the simulation.

Table 7: Controller performance

\begin{tabular}{lcc}
\hline Metric & HNMPC & NMPC \\
\hline$P S E_{\text {Performance }}$ & 0.0973 & 0.2083 \\
$J_{\text {Tperformance }}$ & 0.0012 & 0.0013 \\
THP $P_{\text {Average }}$ & $68.8 \mathrm{t} / \mathrm{h}$ & $65.8 \mathrm{t} / \mathrm{h}$ \\
\hline
\end{tabular}

The simulation results of the controllers are shown in Figures 4, 5, and 6 .

Fig. 4 shows the responses of the CVs during the disturbances. The responses for the continuous MVs are shown in Fig. 5. With the initial increase in hardness, as shown in Fig. 3, it can be observed in Fig. 5 that both controllers compensate for the hardness change by increasing $C F F$ as it is the primary handle for controlling PSE. Both controllers decrease 

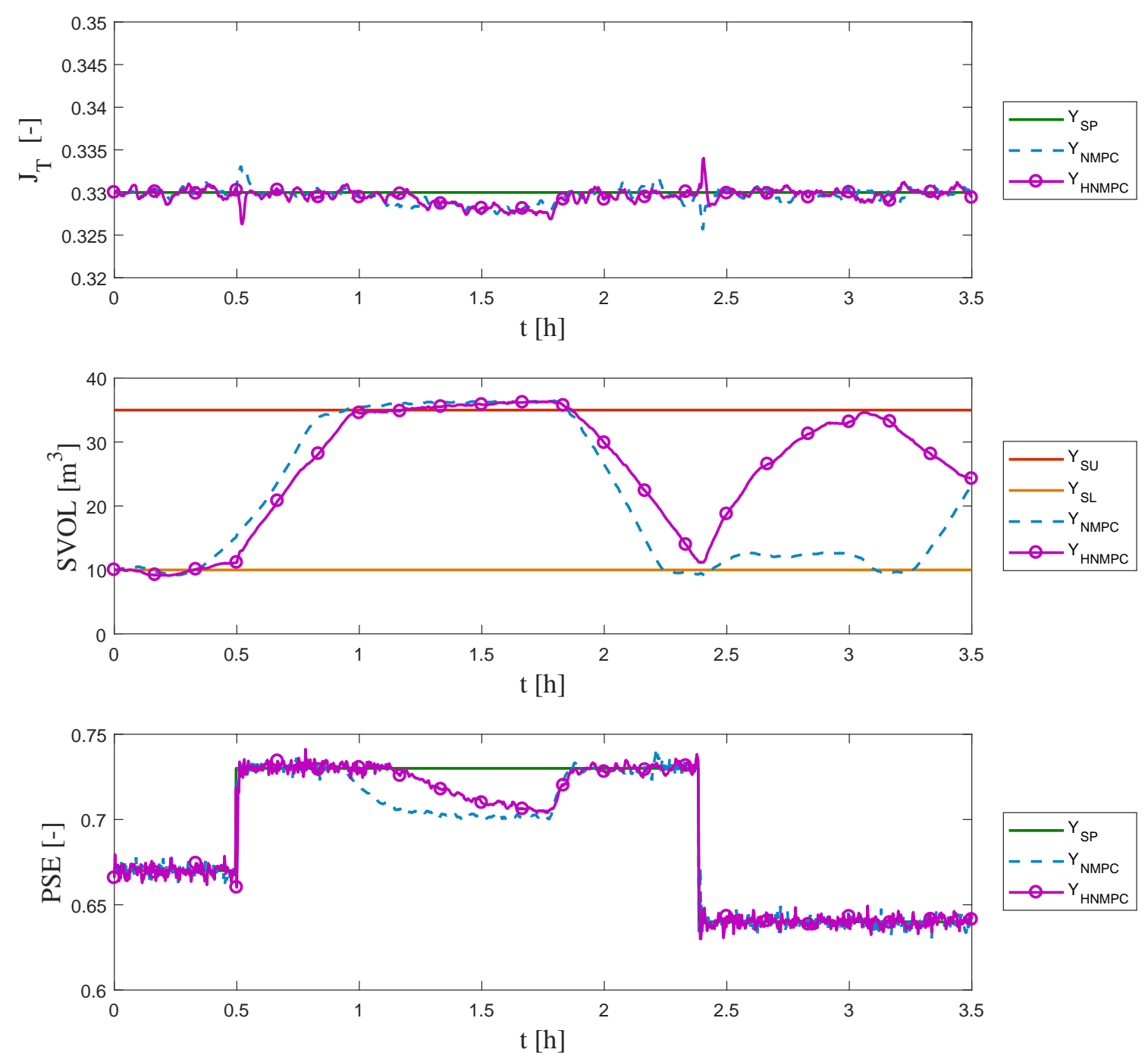

Figure 4: Top: fraction of the mill filled $J_{T}$. Middle: volume of slurry in sump $S V O L$. Bottom: product particle size estimate $P S E$. Legend: $Y_{S P}$ is the desired setpoint, $Y_{S U}$ and $Y_{S L}$ are the upper and lower soft limits for the sump level respectively, $Y_{N M P C}$ and $Y_{H N M P C}$ are the outputs when the NMPC and HNMPC controllers are used respectively.

$M F O$ to compensate for the longer residence time of the material in the mill (due to the increased energy required to break the ore). With the increase in $C F F$ the sump level goes down and $S F W$ is increased to maintain the sump level. Both controllers quickly compensated for the increase in ore hardness.

With the increase in the PSE setpoint the HNMPC switched off a hydrocyclone as seen in Fig. 5. CFF is increased for each hydrocyclone to meet the PSE requirement. The NMPC achieves this by increasing the total $C F F$ to the cluster, and the HNMPC achieves it by switching off a hydrocyclone. For both controllers more particles are discharged through the underflow of the hydrocyclones causing the sump level to increase. The reduction in the number of cyclones (for the HNMPC) results in a higher effective $C F F$ for each 

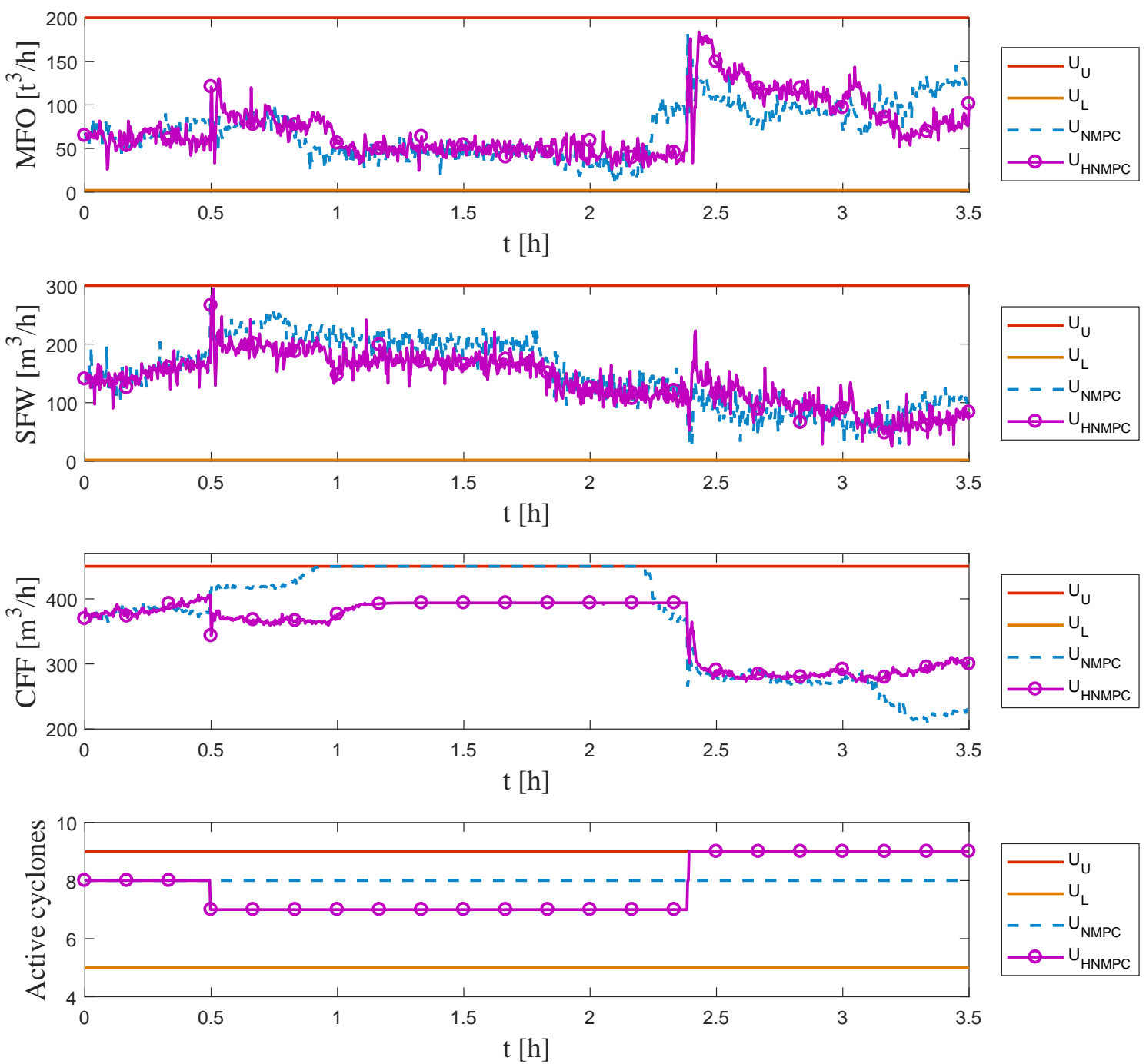

Figure 5: Top: mill solids feed rate $M F O$. Middle Top: sump water feed rate $S F W$. Middle Bottom: hydrocyclone feed flow rate $C F F$. Bottom: number of active cyclones $N_{\text {ActiveCyclones }}$. Legend: $U_{N M P C}$ and $U_{H N M P C}$ are the NMPC and HNMPC controller outputs. $U_{U}$ and $U_{L}$ are the hard constraints for the upper and lower limits of the MVs respectively.

individual hydrocyclone with a lower total $C F F$ to the cluster. The HNMPC benefits from a reduced circulating load over the NMPC (due to the reduced total $C F F$ and the slower sump level increase). With the increased hardness of ore coupled with the $P S E$ increase neither controller can maintain $P S E$ when the sump is ultimately at maximum capacity. $P S E$ has a constant ramp down from setpoint as all possible handles for controlling the $P S E$ are at their constraints. Alternatively the option is available to switch off one more hydrocyclone; however the controller does not consider this move as the sump is already at it's maximum operating capacity and switching off a hydrocyclone results in a lower $C F F$, and therefore to maintain the mass balance over the sump $S F W$ has to decrease, which increases the $C F D$ and therefore further reduces classifier performance. The HNMPC 

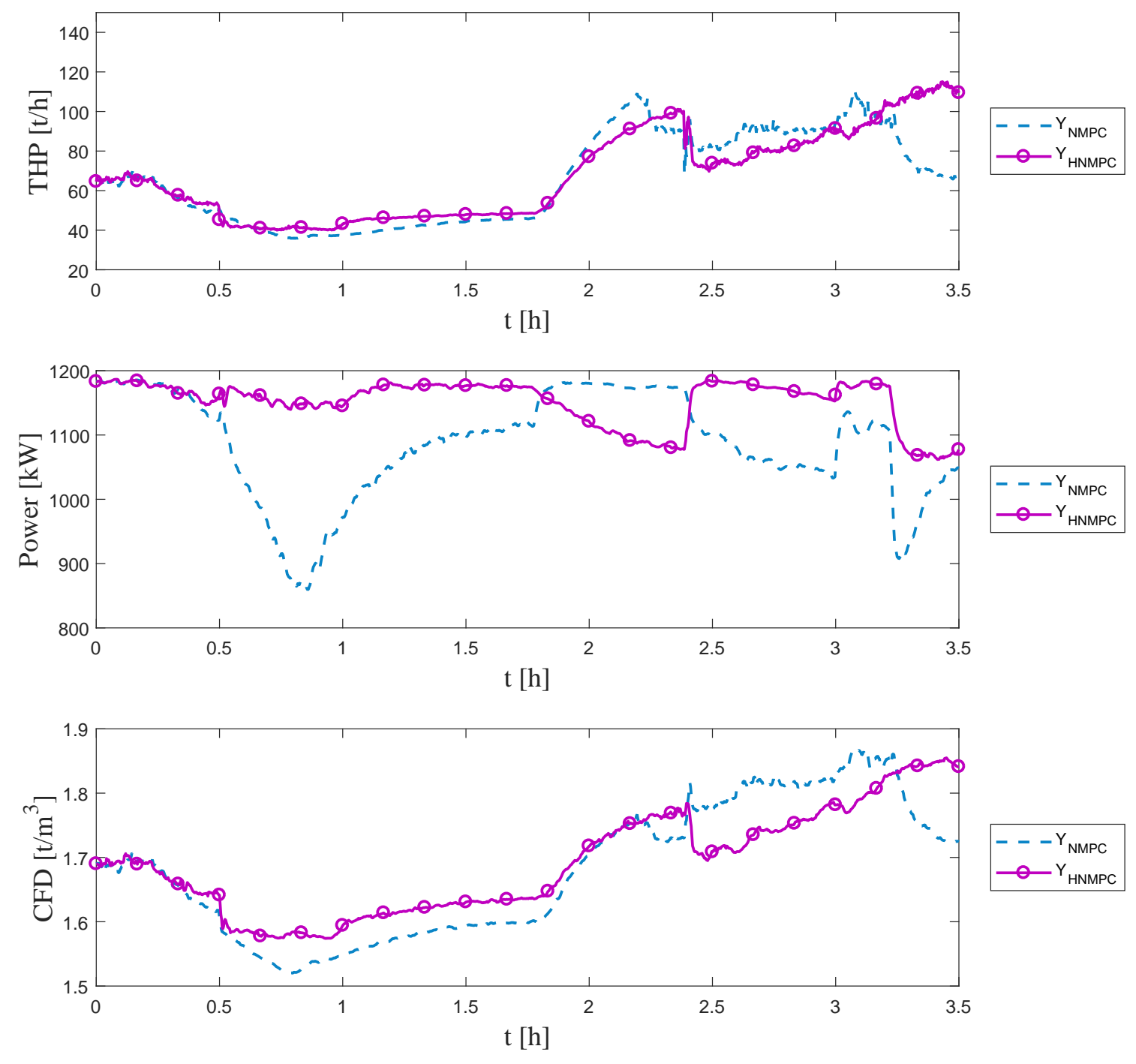

Figure 6: Top: throughput THP. Middle: mill power draw $P_{\text {mill }}$. Bottom: hydrocyclone feed density $C F D$. Legend: $Y_{N M P C}$ and $Y_{H N M P C}$ are the outputs when the NMPC and HNMPC controllers are used respectively.

controller can however maintain the setpoint for longer. Both controllers maintain load to within $1 \%$ of the desired setpoint.

When the hardness of the feed ore is decreased, as seen in Fig. 3, the residence time of the material in the mill reduced and more fines are discharged from the mill. To maintain $P S E$ both controllers keep $C F F$ fixed, and the $P S E$ setpoint quickly recovers with the increase in discharge rate of fines from the mill. With the increase in material meeting the quality specification more particles are discharged from the classifier, and the level of the sump decreases. The controllers reduce $S F W$ in order to control the sump level.

When the $P S E$ setpoint drops, both controllers respond the same by decreasing $C F F$. However, as seen from Fig. 5, the HNMPC switched on two additional hydrocyclones. This 
control move is warranted as with the additional hydrocyclones the reduction in $C F F$ is not as much as with only 8 active hydrocyclones. This results in a smaller penalty in the objective function as a result of the rate of change of $C F F$. Additionally, with the softer feed ore, the circuit capacity can be maximised as a higher $C F F$ is possible with 9 hydrocyclones as compared to 8 . This results in a final steady-state condition where a higher throughput is possible while maintaining PSE. Should the process conditions return to the initial conditions, the HNMPC can switch off a hydrocyclone to achieve the same feed rate per hydrocyclone as the NMPC.

By observing the free variables in Fig. 6 it can be seen that throughout the simulation $C F D$ was kept within limits and is similar for both controllers.

The power usage for both controllers went down when the hardness increased as both controllers decreased $M F O$. However, during the increase in PSE setpoint the power used by the mill was higher for the HNMPC than the NMPC. During the setpoint change the NMPC controller could not maintain $P S E$ and a significant reduction in throughput is observed. At the end of the simulation, the power draw of the mill is higher for the HNMPC than for the NMPC. This is as a result of a higher MFO causing a higher throughput. The power consumption also remains more constant for the HNMPC as a result of the better process stability. Although higher power does not necessarily coincide with higher throughput [49], the HNMPC has a more stable power usage than NMPC.

It is clear from Fig. 6 that the HNMPC uses on average more power $(\mathrm{kW})$ than NMPC, albeit with smaller deviations. However, it should be noted from Table 7 that HNMPC achieves a higher throughput with much less deviation from setpoint for $P S E$ and $J_{T}$ than NMPC. It could be argued that though NMPC uses less mill power, this is at a cost of more MV movement, reduced throughput, and a larger variation in product quality.

The throughput for both controllers is similar throughout the entire simulation. However for the final steady-state condition (at the end of the simulation) the HNMPC allows the circuit to operate at a state where the throughput is $15 \%$ higher than the NMPC. This is due to 9 active hydrocyclones increasing the flow capacity of the hydrocyclone cluster allowing a higher throughput of fines through the circuit (i.e. ensuring that the residence time of the material in the mill is the bottleneck and not the hydrocyclone cluster). Because the HNMPC is able to dynamically simulate the effects of switching hydrocyclones in and out, a resulting benefit is that it improves throughput while maintaining product quality. In response to the disturbances acting on the plant, the HNMPC controller uses the discrete MV to prioritise plant stability during the first half of the simulation, and in the second half to increase throughput. In the case of NMPC the controller is not capable of automatically switching the hydrocyclones which causes a deviation from the desired product quality when ore hardness is increased, and limits the throughput achieved when the ore hardness is reduced from the nominal value (as in the second half of the simulation). When both controllers have the same number of active hydrocyclones, they exhibit similar control actions. As seen in Fig. 6, there is a sharp limitation in the throughput for NMPC after 3.2 hours, when compared to the HNMPC. However, the average throughput for NMPC is $59.3 \mathrm{t} / \mathrm{h}$ until this point, whereas it is $58.9 \mathrm{t} / \mathrm{h}$ for the HNMPC. This was expected since the HNMPC achieved a higher product quality during that time (closer to the desired value than the NMPC) and therefore a lower 
throughput was expected due to the inverse relationship between throughput and quality. Throughput should only be maximised if the product quality is achieved.

Similarly from 2.3 hours to the end of the simulation when the feed size distribution was disturbed, as seen in Fig. 3, both controllers were able to easily compensate for the additional disturbance and maintain the CV setpoints.

Both controllers required similar computational effort. In situations where the minimum fitness function value was achieved over the receding horizon, the HNMPC took on average $0.4 \mathrm{~s}$ to solve, while the NMPC took 0.5s. Similarly in cases where the controller reached the maximum number of iterations (for example just after disturbance or setpoint change), then the HNMPC takes 6s to solve, while the NMPC takes $7 \mathrm{~s}$. These values depend on the maximum number of iterations chosen for each solver, and in both cases the maximum number of iterations was chosen so that the control solution tends the process to the desired operating point. Both controllers executed well within time of the execution interval of 10 seconds. These are promising results for the genetic algorithm based HNMPC since it included additional MVs and mixed integer dynamics.

In a simple case where only one hydrocyclone can be switched on or off per iteration, three parallel NMPC controllers could be considered to evaluate if switching will be beneficial, however it will increase computational effort. During nominal conditions no switching will be required, and therefore one NMPC will execute within $0.5 \mathrm{~s}$, while the parallel NMPC's will take 7s. The average computational effort is therefore increased since the parallel pool of controllers will take $7 \mathrm{~s}$ to solve at each iteration. This is an avoidable situation with the HNMPC and is therefore not recommended.

\section{Discussion and Conclusion}

A continuous time ROM ore grinding mill circuit model was expanded into a hybrid model which explicitly describes the discrete dynamics of switching cyclones in a cluster of cyclones. The parameters for the hydrocyclone were re-fitted to ensure the correct steadystate for the circuit with the hydrocyclone cluster model.

A base case NMPC controller was designed and implemented to compare its performance against that of a controller that can incorporate discrete switching. An HNMPC was developed using the non-linear model and a genetic algorithm as the solver. The controllers were tested in a simulation with large changes in feed ore hardness and product quality setpoints. During the dynamic simulation the HNMPC showed promise in switching cyclones to maintain operating setpoints. An advanced regulatory controller would first have to wait for a certain MV to hit a constraint to switch an element. However, the HNMPC can anticipate when switching is required and can therefore reject disturbances more quickly. Similarly a static optimisation objective can be used to implement switching rules, but then the switching effect will be a disturbance for the NMPC and dynamic optimisation benefits are not achieved.

Over the duration of the simulation the PSE performance for the HNMPC was double that of the NMPC as the average particle size error squared was halved with the HNMPC. 
Both controllers controlled the load in the mill adequately. An average throughput increase of $4.8 \%$ was recorded for the HNMPC over the NMPC over the duration of the simulation.

In this paper some simplifying assumptions were made in order to demonstrate the advantages that HNMPC can bring when using a hydrocyclone cluster as an additional manipulated variable. These assumptions include that the process model was assumed accurate, transport delays were omitted, ideal sensors and actuators were assumed, and full-state feedback was used. In reality, some important grinding circuit variables are not measured, sensors and actuators are not ideal, and transport delays are not negligible.

These issues do however impact on all controllers, including model based ones, and should be carefully considered as addressed briefly in what follows.

Full-state feedback was assumed in this paper. This was done noting the development of various state estimators for grinding mill circuits [31, 41, 42, 43], and a normal distribution of state noise larger than the average errors of those estimators was added to the full-state feedback in an attempt to make the simulations more realistic.

The simulation further did not assume any model mismatch, apart from the disturbances induced. These can however be mitigated as shown in [45] if not too severe. For practical implementation of advanced process controllers (such as HNMPC) it is important to note that if the ranges of the controller MVs and CVs are set up correctly, even in the presence of quite severe model mismatch, plant stability can be ensured with proper operation of the base-layer control loops and conservative tuning of the HNMPC.

Implementing an HNMPC is similar to implementing an NMPC which is becoming easier to implement due to the increased availability of suitable vendor platforms (see e.g. [23]). What remains a challenge is to accurately model the plant to be controlled, and to keep this model up to date.

The HNMPC and NMPC respond identically to transport delay mismatch between the simulation model and the control model. Both can cope with transport delay errors of up to 6 iterations (i.e. 60s) before any noticeable controller performance degradation is noticed. However, in this study since the effect is the same on both controllers it was not considered or included, but it is an important model variable that should be carefully modelled for industrial implementation.

The key contribution as shown in this study was that there is underlying benefit in incorporating discrete process input variables in the controller formulation. The benefits were illustrated quantitatively (given the ideal simulation environment and the performance metrics), but also qualitatively (considering all the assumptions made, but noting the types of control moves made). The benefits noted were improved stability and improvements in throughput when manipulating the switching of hydrocyclones in a cluster.

\subsection{Future work}

This article presented the formulation of a hybrid predictive controller that allows for the incorporation of discrete process input variables directly into the control problem. This means that switching of these discrete MVs are no longer left to operator discretion or additional control layers. However, towards the final industrial implementation of such a controller there are still some issues that should be investigated, including: 
- A state estimator should be developed for the hybrid model to estimate the states. The study should preferably use a different simulation model and controller model to illustrate the capabilities of the controller. If sufficient results are achieved using state estimation, an industrial implementation should definitely be considered.

- HNMPC could potentially be used in the plantwide control of grinding mill circuits. The plantwide controller can incorporate the downstream flotation circuit into the hybrid model, as well as the upstream stockpiles (in order to activate flotation banks or to choose ore feed stockpiles).

- Grinding mill circuits with various multiple mills in parallel can benefit from implementing economic HNMPC to improve the energy efficiency of the circuit in real time by switching grinding mill stages. A time-of-use term can be added to the objective function to optimise the energy usage of a circuit as a whole.

- Fault tolerant control can benefit from the additional discrete MVs [50]. For example if the hydrocyclone cluster feed flow were to get stuck on a value due to a faulty control loop or a faulty control valve, and the fault is identified the controller could consider manipulating hydrocyclones in the cluster instead of opting to switch off the plant.

\section{References}

[1] J. D. le Roux, I. K. Craig, D. G. Hulbert, A. L. Hinde, Analysis and validation of a run-ofmine ore grinding mill circuit model for process control, Minerals Engineering 43-44 (2013) 121-134. doi:10.1016/j.mineng.2012.10.009.

[2] X. Chen, J. Zhai, S. Li, Q. Li, Application of model predictive control in ball mill grinding circuit, Minerals Engineering 20 (11) (2007) 1099-1108. doi:10.1016/j.mineng.2007.04.007.

[3] L. C. Coetzee, I. K. Craig, E. C. Kerrigan, Robust nonlinear model predictive control of a run-of-mine ore milling circuit, IEEE Transactions on Control Systems Technology 18 (1) (2010) 222-229.

[4] B. Matthews, I. K. Craig, Demand side management of a run-of-mine ore milling circuit, Control Engineering Practice 21 (6) (2013) 759-768. doi:10.1016/j.conengprac.2013.02.005.

[5] R. E. McIvor, J. A. Finch, A guide to interfacing of plant grinding and flotation operations, Minerals Engineering 4 (1) (1991) 9-23. doi:10.1016/0892-6875(91)90114-B.

[6] C. Sosa-Blanco, D. Hodouin, C. Bazin, C. Lara-Valenzuela, J. Salazar, Economic optimization of a flotation plant through grinding circuit tuning, Minerals Engineering 13 (10) (2000) 999-1018. doi:10.1016/S0892-6875(00)00086-8.

[7] C. Muñoz, A. Cipriano, Integrated system for supervision and economic optimal control of mineral processing plants, Minerals Engineering 12 (6) (1999) 627-643. doi:10.1016/S0892-6875(99)00048-5.

[8] D. Wei, I. K. Craig, Economic performance assessment of two ROM ore milling circuit controllers, Minerals Engineering 22 (9-10) (2009) 826-839. doi:10.1016/j.mineng.2009.02.013.

[9] J. D. le Roux, S. Skogestad, I. K. Craig, Plant-wide control of grinding mill circuits: Top-down analysis, IFAC-PapersOnLine 49 (20) (2016) 72-77. doi:10.1016/j.ifacol.2016.10.099.

[10] S. Skogestad, Plantwide control: The search for the self-optimizing control structure, Journal of Process Control (5) (2000) 1-30.

[11] D. Wei, I. K. Craig, Grinding mill circuits: A survey of control and economic concerns, International Journal of Mineral Processing 90 (1-4) (2009) 56-66. doi:10.1016/j.minpro.2008.10.009.

[12] I. K. Craig, D. G. Hulbert, G. Metzner, S. P. Moult, Optimized multivariable control of an industrial run-of-mine milling circuit, Journal of the South African Institute of Mining and Metallurgy 92 (6) (1992) 169-176. 
[13] B. Muller, P. L. de Vaal, Development of a model predictive controller for a milling circuit, Journal of the South African Institute of Mining and Metallurgy 100 (7) (2000) 449-454.

[14] M. Hadizadeh, A. Farzanegan, M. Noaparast, Supervisory fuzzy expert controller for SAG mill grinding circuits: Sungun copper concentrator, Mineral Processing and Extractive Metallurgy Review 38 (3) (2017) 168-179. doi:10.1080/08827508.2017.1281133.

[15] I. K. Craig, D. G. Hulbert, G. Metzner, S. P. Moult, Extended particle-size control of an industrial run-of-mine milling circuit, Powder Technology 73 (1992) 203-210.

[16] M. A. Naidoo, R. Padhi, I. K. Craig, A new nonlinear suboptimal control design approach for milling circuits, in: 19th IFAC World Congress, Cape Town, South Africa, 24-29 Aug., 2014. IFAC Proceedings Volumes, Vol. 47, Issue 3, 2014, pp. 9804-9809. doi:10.3182/20140824-6-ZA-1003.02130.

[17] J. D. Le Roux, L. E. Olivier, M. A. Naidoo, R. Padhi, I. K. Craig, Throughput and product quality control for a grinding mill circuit using non-linear MPC, Journal of Process Control 42 (June) (2016) 35-50. doi:10.1016/j.jprocont.2016.04.007.

[18] S. Botha, I. K. Craig, J. D. le Roux, Switching cyclones to increase product particle size range for ore milling circuits, in: IFAC Workshop on Automation in Mining, Minerals and Metal Industry, Oulu, Finland, 25-27 Aug., 2015. IFAC-PapersOnLine, Vol. 28, Issue 17, 2015, pp. 92-97. doi:10.1016/j.ifacol.2015.10.084.

[19] F. Estrada, Hybrid model predictive control for grinding plants, in: 19th IFAC World Congress, Cape Town, South Africa, 24-29 Aug., 2014. IFAC Proceedings Volumes, Vol. 47, Issue 3, 2014, pp. 1151211517. doi:10.3182/20140824-6-ZA-1003.02739.

[20] S. J. Qin, T. A. Badgwell, A survey of industrial model predictive control technology, Control Engineering Practice 11 (7) (2003) 733-764. doi:10.1016/S0967-0661(02)00186-7.

[21] D. E. Seborg, T. F. Edgar, D. A. Mellichamp, F. J. Doyle, Process dynamics and control, 3rd Edition, John Wiley \& Sons, New York, 2010.

[22] C. E. Garcia, D. M. Prett, M. Morari, Model predictive control: Theory and practice: A survey, Automatica 25 (3) (1989) 335-348.

[23] L. C. Coetzee, Stabilising and optimising a primary closed - loop milling circuit feeding a flotation circuit using StarCS RNMPC, in: 19th IFAC World Congress, Cape Town, South Africa, 24-29 Aug., 2014. IFAC Proceedings Volumes, Vol. 47, Issue 3, 2014, pp. 9786-9791. doi:10.3182/20140824-6-ZA1003.01396.

[24] C. J. Muller, I. K. Craig, Cooling Water System Modelling for Control and Energy Optimisation Purposes, in: 19th IFAC World Congress, Cape Town, South Africa, 24-29 Aug., 2014. IFAC Proceedings Volumes, Vol. 47, Issue 3, 2014, pp. 3973-3978. doi:10.3182/20140824-6-ZA-1003.01030.

[25] D. Xiao, D. Song, L. Peng, T. Li, Hybrid model predictive control based on modified particle swarm optimization, in: Proceedings Bio-Inspired Computing: Theories and Applications (BIC-TA), IEEE Fifth International Conference, Changsha, China, 23-26 Sept., 2010, pp. 385-390.

[26] C. J. Muller, I. K. Craig, Economic hybrid non-linear model predictive control of a dual circuit induced draft cooling water system, Journal of Process Control 53 (2017) 37-45. doi:10.1016/j.jprocont.2017.02.009.

[27] P. Karelovic, E. Putz, A. Cipriano, A framework for hybrid model predictive control in mineral processing, Control Engineering Practice 40 (2015) 1-12.

[28] A. Bemporad, M. Morari, Control of systems integrating logic, dynamics, and constraints, Automatica 35 (3) (1999) 407-427. doi:10.1016/S0005-1098(98)00178-2.

[29] T. J. Napier-Munn, S. Morrell, R. D. Morrison, T. Kojovic, Mineral comminution circuits: Their operation and optimisation, Vol. 2, Julius Kruttschnitt Mineral Research Centre, University of Queensland, Australia, 1996.

[30] S. Morrell, A new autogenous and semi-autogenous mill model for scale-up, design and optimisation, Minerals Engineering 17 (3) (2004) 437-445. doi:10.1016/j.mineng.2003.10.013.

[31] T. A. Apelt, S. P. Asprey, N. F. Thornhill, Inferential measurement of SAG mill parameters II: State estimation, Minerals Engineering 15 (12) (2002) 1043-1053. doi:10.1016/S0892-6875(02)00229-7.

[32] J. D. le Roux, I. K. Craig, Reducing the number of size classes in a cumulative rates model 
used for process control of a grinding mill circuit, Powder Technology 246 (2013) 169-181. doi:10.1016/j.powtec.2013.05.018.

[33] F. N. Shi, T. J. Napier-Munn, Effects of slurry rheology on industrial grinding performance, International Journal of Mineral Processing 65 (3) (2002) 125-140.

[34] F. D. Torrisi, A. Bemporad, HYSDEL: A tool for generating computational hybrid models for analysis and synthesis problems, IEEE Transactions on Control Systems Technology 12 (2) (2004) 235-249. doi:10.1109/TCST.2004.824309.

[35] R. P. King, Modeling and simulation of mineral processing systems, Elsevier Science, Boston, 2012.

[36] D. Cirulis, J. Russell, Cyclone Monitoring System Improves Operations at KUC's Copperton Concentrator, Engineering and Mining Journal 212 (10) (2011) 44-49.

[37] C. J. Muller, I. K. Craig, Energy reduction for a dual circuit cooling water system using advanced regulatory control, Applied Energy 171 (2016) 287-295. doi:10.1016/j.apenergy.2016.03.069.

[38] E. Putz, A. Cipriano, Hybrid model predictive control for flotation plants, Minerals Engineering 70 (2015) 26-35. doi:10.1016/j.mineng.2014.08.013.

[39] K. Nageswararao, D. M. Wiseman, T. J. Napier-Munn, Two empirical hydrocyclone models revisited, Minerals Engineering 17 (5) (2004) 671-687. doi:10.1016/j.mineng.2004.01.017.

[40] C. Song, P. Wang, H. A. Makse, A phase diagram for jammed matter, Nature 453 (7195) (2008) 629.

[41] L. E. Olivier, B. Huang, I. K. Craig, Dual particle filters for state and parameter estimation with application to a run-of-mine ore mill, Journal of Process Control 22 (4) (2012) 710-717. doi:10.1016/j.jprocont.2012.02.009.

[42] J. A. Herbst, W. T. Pate, Object components for comminution system softsensor design, Powder Technology 105 (1-3) (1999) 424-429. doi:10.1016/S0032-5910(99)00168-0.

[43] L. E. Olivier, I. K. Craig, Y. Q. Chen, Fractional order and BICO disturbance observers for a run-of-mine ore milling circuit, Journal of Process Control 22 (1) (2012) 3-10. doi:10.1016/j.jprocont.2011.11.001.

[44] J. D. le Roux, A. Steinboeck, A. Kugi, I. Craig, An EKF observer to estimate semi-autogenous grinding mill hold-ups, Journal of Process Control 51 (2017) 27-41. doi:10.1016/j.jprocont.2016.12.006.

[45] L. E. Olivier, I. K. Craig, Model-plant mismatch detection and model update for a run-of-mine ore milling circuit under model predictive control, Journal of Process Control 23 (2) (2013) 100-107.

[46] A. A. A. Esmin, G. Lambert-Torres, A. C. Zambroni de Souza, A hybrid particle swarm optimization applied to loss power minimization, IEEE Transactions on Power Systems 20 (2) (2005) 859-866. doi:10.1109/TPWRS.2005.846049.

[47] K. Mitra, R. Gopinath, Multiobjective optimization of an industrial grinding operation using elitist nondominated sorting genetic algorithm, Chemical Engineering Science 59 (2004) 385-396. doi:10.1016/j.ces.2003.09.036.

[48] D. Whitley, A genetic algorithm tutorial, Statistics and Computing 4 (2) (1994) 65-85.

[49] M. S. Powell, A. P. van der Westhuizen, A. N. Mainza, Applying grindcurves to mill operation and optimisation, Minerals Engineering 22 (7-8) (2009) 625-632. doi:10.1016/j.mineng.2009.01.008.

[50] L. E. Olivier, I. K. Craig, Should I shut down my processing plant? An analysis in the presence of faults, Journal of Process Control 56 (2017) 35-47. 